\title{
The Development of Primary Care Information Technology in the United Kingdom
}

\author{
Simon de Lusignan, MBBS, MSc, MD, FRCGP, FBCS CITP; \\ Tom Chan, RGN, RMN, MSc, PhD
}

\begin{abstract}
Background: UK primary care is highly computerized; initially led by enthusiastic general practitioners who developed their own systems. This preceded the development of a National Health Service information strategy and an ambitious National Programme for IT. Model: A 4-element model is proposed to explain the development of information technology: (1) individual clinician choice; (2) integration into the clinical task-usually an office visit; (3) technological developments; and (4) organizational factors. Conclusion: All 4 elements of this model have been tilted in favor of the utilization of information technology; lessons from the United Kingdom may help other health systems looking to implement information technology systems in primary care. Key words: computer systems, family practice, informatics, medical records, primary bealthcare
\end{abstract}

Historical perspective (GP) and they can be shared with the patient; and a printer that produces presckiptions is care has been highly comput erized for some years with nearly all family physicians using computers during the clinical consultation. UK general practice comput ing is among the most advanced in the world alongside Scandinavia and the Netherlands (Taylor \& Leitman, 2002). In the United Kingdom, the patient typically sits on the right side of a general practitioner's consulting room desk rather than being interviewed across the desk; the computer keyboard, mouse, and monitor are in front of the general practitioner

generally located within easy reach, on the left side of the doctor (Schade et al., 2006) (Fig 1).

Initially, UK primary care computing was largely led by GPs who developed their own computer system to hold what we would regard by today's standards as an embryonic electronic medical record. These early sys tems replaced the need to keep a manual "age-sex register" - a card system organized by age and gender, which were filed alphabetically. The age-sex register was used for monitoring preventive procedures such as childhood immunizations. These early com-

From the Division of Community Health Sciences, puterized systems also had simple coding sysSt. George's University of London, London, United Kingdom. ease registers terns which enabled computerization of "dis-

The authors thank the members of the biomedical informatics group at St. Georges S Unversity of London; the tiptestcity The the was a mulsystems, and gradu-Primary Health Care Specialist Group and Health In-

formatics Forum of the British Computer Society, and ally by natural selection, the number of ven the Primary Care Working Group of the European Federation for Medical Informatics for helpful discussions than declined from more 3 main suppliers in England and about developing primary care IT.

Wales and a single dominant state-funded sysCorresponding author: Simon de Lusignan, MBBS, MSc, tem in Scotland; all using a variant of the same MD, FRCGP, FBCS CITP, Division of Community Health Sciences, St. George's University of London, London, clinical coding system (Read Codes). A simUnited Kingdom SW17 ORE (e-mail: slusigna@sgul.ac.uk). and coding systems has from multiple small suppliers 


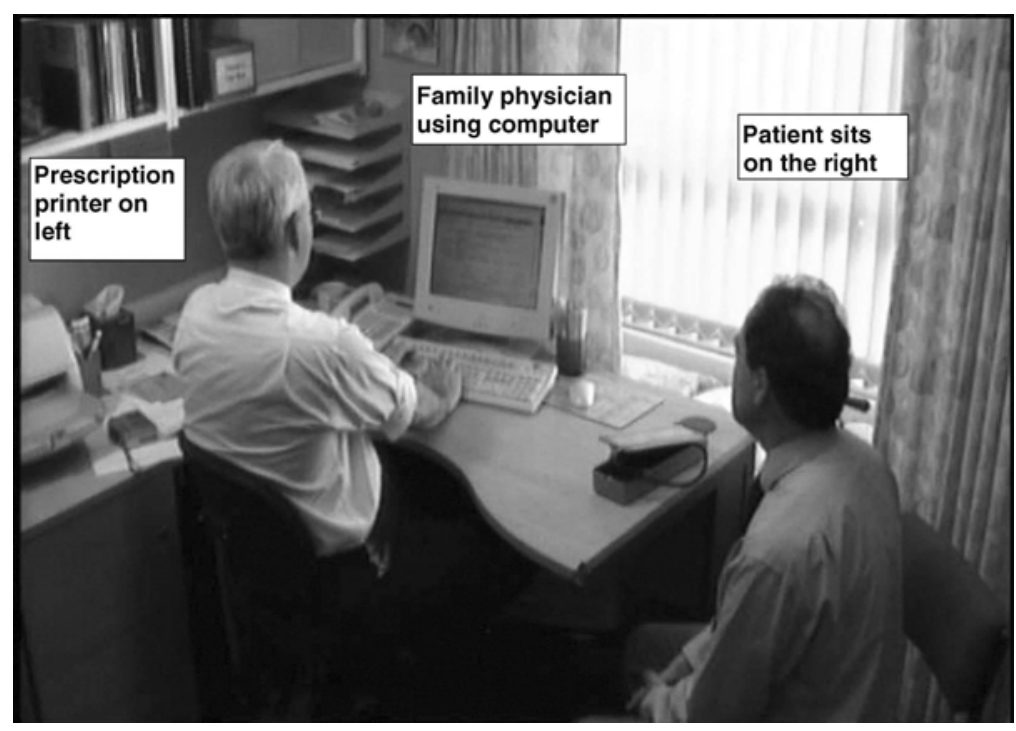

Figure 1. Standard layout for computer-mediated consultations in UK primary care.

(de Lusignan et al., 2004; de Lusignanc,826rati.

Over time, computer functionality improved; the computerization of repeat prescribing (refills of drugs) was probably the most important because this is the only element of computer, which saves functionality time (as well as being more legible and safer) (Mitchell \& Sullivan, 2001). Later, links became established between pathology laboratories and primary care computer systems so that test results could be sent electronically and automatically added to electronic patient records. GPs also received Internet links and e-mail, so they could access electronic resources from their consulting room. Many practices also started to share their data, usually in an anonymized format, for clinical audit, management, and research (de Lusignan et al., 2006). Although many of the brands of GP systems offer innovative ways of working-including online booking of appointments and remote access to medical records - generally, the interface and functionality remain idiosyncratic and vary greatly. The hardware that runs a GP computer system is normally located on individual practice premises and the data within it were usually inaccessible when the clinic was closed.
The impact of the National Programme for IT on primary care

The English National Health Service (NHS) is implementing the largest information technology (IT) infrastructure project in the world: the National Programme for IT (NPfIT) (Brennan, 2005). This is an ambitious plan to connect all NHS computing via an electronic spine. NPfIT should be seen in the context of a wide range of initiatives to set central strategy and quality standards across the NHS. These include a wider range of National Service Frameworks and a Cancer Plan (Department of Health) to set consistent clinical standards; a national body to develop clinical guidelines (National Institute for Health and Clinical Excellence); and the setting up of the Healthcare Commission (Healthcare Commission) as an inspectorate to ensure that standards are implemented.

NHS IT in England has had its successes and frustrations. Successes relevant to primary care include

1. the creation of a new NHS number- a unique identifier for everyone in the NHS. Historically, the central register was manual and NHS numbers were not unique. The new unique identifier has made the population denominator more 
accurate by removing so-called "ghost patients"(Ashworth et al., 2005);

2. electronic transfer of records from one GP to another; until recently GPs had to print computer records and have the next practice to reenter them;

3. implementing an application to monitor achievement of financially incentivized chronic disease management targets in a new pay-forperformance scheme;

4. improvement and standardization of drug alerts;

5. early access to limited hospital and clinic data; and

6. an online tool kit for GP annual appraisal. There have been mixed reactions to other parts of the program:

1. "Choose and Book" — an online system for choosing outpatient bookings in real time. The principal problem is how long it takes to run in a short GP consultation.

\section{Moves toward hosted systems-} where practices do not have their "own"server. There are concerns that this may be less reliable and less responsive to the needs of the practice than current practice-based systems.

3. Electronic transfer of prescriptions from GP to pharmacy may have limited benefits, but many question why this should be a priority.

4. "Health space" is an Internet resource allowing patients to view their summary electronic patient record. It may be better for GP system vendors to provide patients, who want its access to their full GP record. The NHS summary record can be updated by many NHS bodies and GPs cannot edit it.

5. GPs have been given a limited choice of brand of computer system-but for understandable practical reasons, localities want to restrict this to a limited range of vendors; often only 2 .

6. The National Care Record Service is limited in the extent of medical information it will hold and hence, there are concerns as to how useful this limited record might be. Initially, GPs won't be able to edit Care Record Service be cause its entries are in SNOMED CT (Systematized Nomenclature of MedicineClinical Terms) and primary care still uses Read Codes.

7. With the potentially wider access to and sharing of clinical data, there are general worries about adequacy of security and privacy.

\section{A model to explain the computerization of UK Primary Care}

We propose that 4 elements have contributed to the increasing use of IT in UK primary care in recent years (Fig 2):

1. Individual clinicians choose to use IT because they perceive benefits.

2. Use of IT at the point of delivery of care is feasible within clinician's workflow.

3. Technological developments have enabled the processing and communication of data.

4. Organizational incentives have existed at all levels of the health system.

5. We suggest that all 4 have been tipped in favor of using information technology in UK primary care.

\section{INDIVIDUAL CLINICIANS CHOOSE TO USE INFORMATION TECHNOLOGY \\ Clinician motivation}

It is probably impossible to introduce IT unless clinicians want to use it and peer group support and education are probably extremely important. It has been recognized for some time that clinicians form a complex social network, and positive peer educative support is important in IT implementation (Anderson et al., 1994). We also know that care without the support of IT is not disastrous, so there is no overwhelming reason to move on from well-adapted paper systems; a recent study reports no improvement in the quality of care in consultations where IT is used (Linder et al., 2007).

\section{Knowledge and skills}

In the United Kingdom, most early attempts to improve uptake focused on providing the 


\begin{tabular}{|c|c|c|}
\hline $\begin{array}{l}\text { 1. Clinician choice } \\
\text { - Clinician motivation } \\
\text { Work with the complex social network } \\
\text { where peer group is important } \\
\text { - Knowledge and skills } \\
\text { May assist diffusion of innovation } \\
\text { Time to adjust } \\
\text { Gradual adoption of IT alongside paper } \\
\text { Financial incentives } \\
\text { Financial incentives have accelerated } \\
\text { computer use }\end{array}$ & & $\begin{array}{l}\text { 2. Use at point of care } \\
\text { IT supports biomedicine best } \\
\text { Coding systems + computing power } \\
\text { supports biomedicine better than } \\
\text { psychosocial problems } \\
\text { No standard way of using IT } \\
\text { None was imposed, which was OK in } \\
\text { the context of no evidence-based } \\
\text { C Context is critical } \\
\text { Context of recording needs to be } \\
\text { understood if secondary use is made of } \\
\text { data }\end{array}$ \\
\hline & $\begin{array}{l}\text { Development } \\
\text { of IT in } \\
\text { primary care }\end{array}$ & \\
\hline $\begin{array}{l}\text { 3. Technological advances } \\
\text { - Human-computer interface } \\
\text { Simple, largely character user interfaces } \\
\text { have been more successful than graphical } \\
\text { interfaces in some circumstances. } \\
\text { - Linkage } \\
\text { To pathology laboratories, etc. have } \\
\text { promoted IT uptake } \\
\text { Integration } \\
\text { Offers allure of safer more efficient care } \\
\text { for patients } \\
\text { - Information security } \\
\text { Technical developments have been } \\
\text { important-But needs more certainty } \\
\text { whether "Opt out" is OK for data sharing }\end{array}$ & & $\begin{array}{l}\text { 4. Organisational factors } \\
\text { Practice/clinic level } \\
\text { Lowering/removal of financial have } \\
\text { been important in allowing investment } \\
\text { Locality/regional level } \\
\text { Incentives for IT associated with other } \\
\text { policy priorities } \\
\text { Secondary use of data for clinical audit } \\
+ \text { quality improvement } \\
\text { Exational policy } \\
\text { Explicit national evidence-based } \\
\text { standards + culture of clinical } \\
\text { governance } \\
\text { IT strategy supporting moves toward } \\
\text { an integrated system }\end{array}$ \\
\hline
\end{tabular}

Figure 2. Model of factors tipped in favor of the development of primary care information technology.

knowledge and skills to use IT, including basic keyboard skills, and to "code"clinical data. However, this was at a time when technologies, such as e-mail, were not as pervasive as they are now. Education about how to make best use of the computer system remains popular. The usergroup conferences of the major brands of UK GP computer system remain some of the largest primary care conferences in the country.

Time to adjust

Many primary care clinicians initially used IT in parallel with paper. They often started just issuing repeat prescriptions (drug refills) on the computer because this was faster than writing out prescriptions by hand. Much of the other functionality was initially under-used, with progressive adoption over time.
For several years after the millennium, many moved toward "paperless practice" but without any definition of the term, or widespread implementation (Thiru et al., 2002). Data quality and the use of computers for auditing the quality of care were steadily increasing with growing acceptance of IT as part of the consultation. Our own study of diabetes data shows this improvement over the years before 2004, when the new financially incentivized contract was introduced. The progressive improvement in data recording and quality of care (except perhaps in the management of obesity in diabetes) is shown in Figure 3 (de Lusignan et al., 2005).

Financial incentives change behavior

A major step change in computer use has come with the implementation of financially 
(a) Body mass index

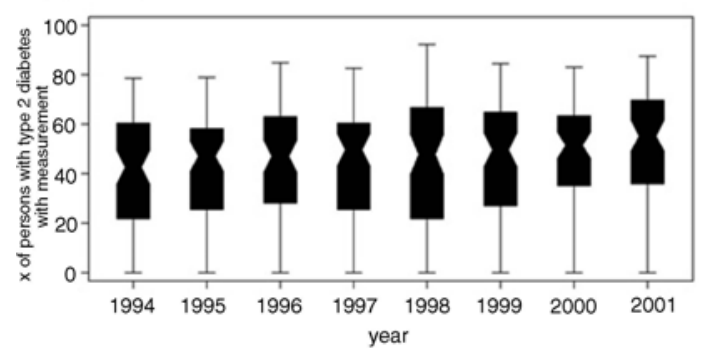

(c) HbA1c

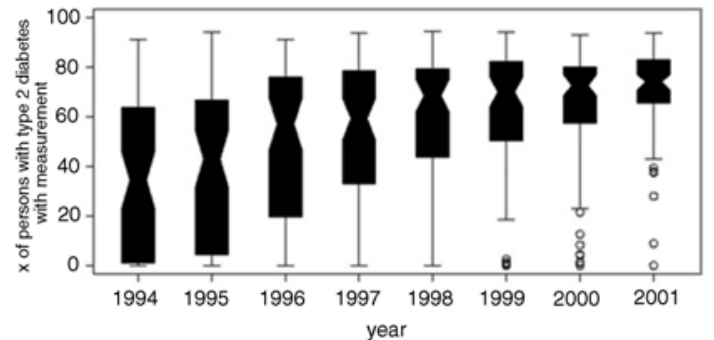

(b) Blood pressure

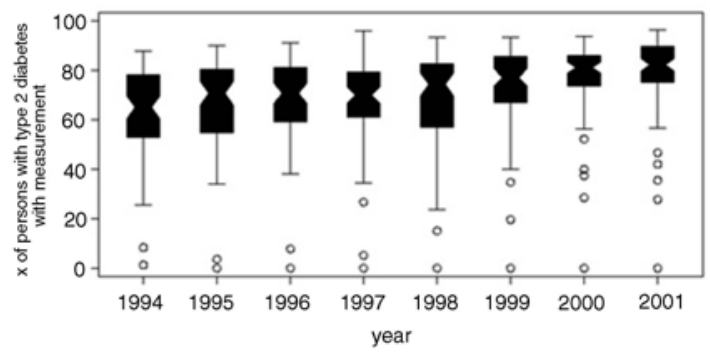

(d) Cholesterol

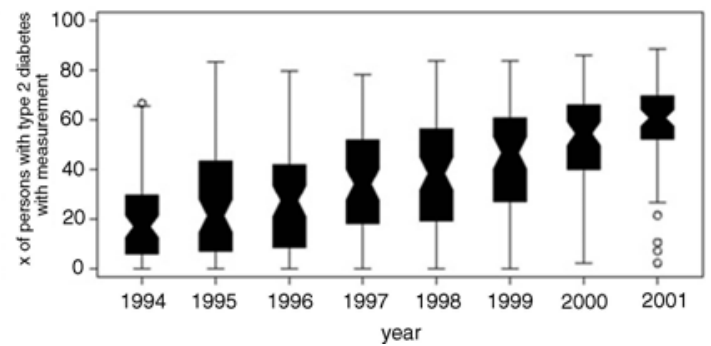

Figure 3. Distribution of the practice percentage of persons with diabetes with a risk factor measured by year. Boxes indicate the median, lower, and upper quartiles Whiskers extend to the practice immediately preceding 1.5 times the interquartile range from the median. Practices lying outside this range are individually plotted. Percentage of all measurements that were numeric and valid were for each risk factor: (a) body mass index (95\%), (b) blood pressure (97\%), (c) HbA1c (61\%), and (d) cholesterol (91\%) (de Lusignan et al., 2005).

incentivized chronic disease management targets in a new pay-for-performance scheme introduced in 2004. These set out standards for the management of a wide range of chronic conditions. Most of the quality targets included setting up a disease register for people with the condition (eg, diabetes) and seeing that routine observations are carried out (eg, blood pressure monitoring) that appropriate targets are achieved (eg, blood pressure $<145 / 85 \mathrm{~mm} \mathrm{Hg}$ ). The only route for payment is through automated submission of routinely collected computer data. This policy initiative changed the attitude to computer use very rapidly.

\section{USING IT AT THE POINT OF CARE}

\section{IT is best adapted to support the biomedical model}

Clinical computer systems tend to be orientated toward the biomedical model rather than a holistic approach. Computers are good at processing numerical data (eg, glycosylated hemoglobin control in a general practice diabetic population) and providing quantitative data on quality of care. However, the process of clinical coding of a problem tends to force a biomedical label, which is sometimes unhelpful. Computers are less good at coding vague complaints, social diagnoses, or physical manifestations of underlying psychological problems, which are often features of clinical consultations in primary care; although not all coding systems are the same. The United Kingdom has opted for comprehensive classification systems capable of coding most clinical concepts, whereas other countries successfully use more limited classifications (de Lusignan, 2006). Some factually corrected information (eg, depression; termination of pregnancy) can also be stigmatizing to patients and recording it can impair the doctor-patient relationship (de Lusignan et al., 2003). 
No model for computer use in the clinical consultation

No widely accepted model exists of how to incorporate the computer into the clinical consultation. Computer use was described 20 years ago as being "minimal"-mainly used when the patient has left the room; "block"-where the clinician stops as if answering the phone to use the computer; or "conversational" - with the computer used on and off through the consultation (Fitter \& Cruickshank, 1983). Many trainee GPs in the United Kingdom are advised not to use the computer while the patient is in the room. Although avoiding computer use in the consultation leaves the clinician able to give more attention to the patient, histories recorded at the end of the consultation can be less accurate than recorded during the story unfolds. Early computer "crashes" and over-complex systems that are hard to integrate into normal workflows also undermine confidence in their use (Bates, 2006).

\section{Context is critical}

The context in which most GPs and practice nurses work is from a single office/ consulting room in which they see any problem that their patients present with. Working from a single office makes IT usage much easier to integrate into your workflow in comparison with a hospital doctor who has to move between clinics and visit patients on different wards (Benson, 2006a, 2006b). Individual consultations and records generated from them need to be interpreted within the circumstances of the individual patient. Interpretation of clinical data requires an understating of the context in which it was recorded (Van Der Lei, 1991).

\section{TECHNOLOGICAL DEVELOPMENTS}

\section{Human-computer interface}

Natural selection of human-computer interface has selected a system, which appears old fashioned in comparison with other IT applications. EMIS LV is the most used single variant of any computer system currently in use in England; it is largely a character-based user interface (Fig 3). The character-based user interface of EMIS LV seems faster and needs less hand-eye coordination than using a mouse and maybe faster at prescribing and consequently interfere less in the consultation than mousedriven systems (Fig 4).

\section{Linkage of primary care IT}

Linkage between primary care computer systems and other systems across the NHS has increased, although most are the result of initiatives by individual computer system vendors. Data are received into GP computer systems from pathology laboratories; some practices have online booking of appointments and others are starting to allow patients access to their clinical records. One of the first to do this was the practice of the GP and serial murderer Harold Shipman; the new practice felt that this was an important step toward establishing trust (Hannan \& Webber, 2007). The secondary use of data has also developed, with again most of the networks sharing data from a single vendor (de Lusignan \& Van Weel, 2006).

\section{Integration into enterprise-wide systems}

Moves toward an integrated NHS computer system are making slower progress. Currently, GP computer systems are linked to a National Demographic Service that checks that personal details are up-to-date and practices are generally booking outpatient clinic appointments in real time-accessing booking times in a range of hospitals and letting patients choose which one they would like to go to. We are also starting to transfer patient records when they move practice electronically; up to now, we have had to print patient records and transfer them manually. The NHS aspires to give all patients access to their summary records online through a portal called "Health Space," this program is currently being rolled out.

\section{Information security}

Security and the necessary permissions now appear to be a greater limitation 


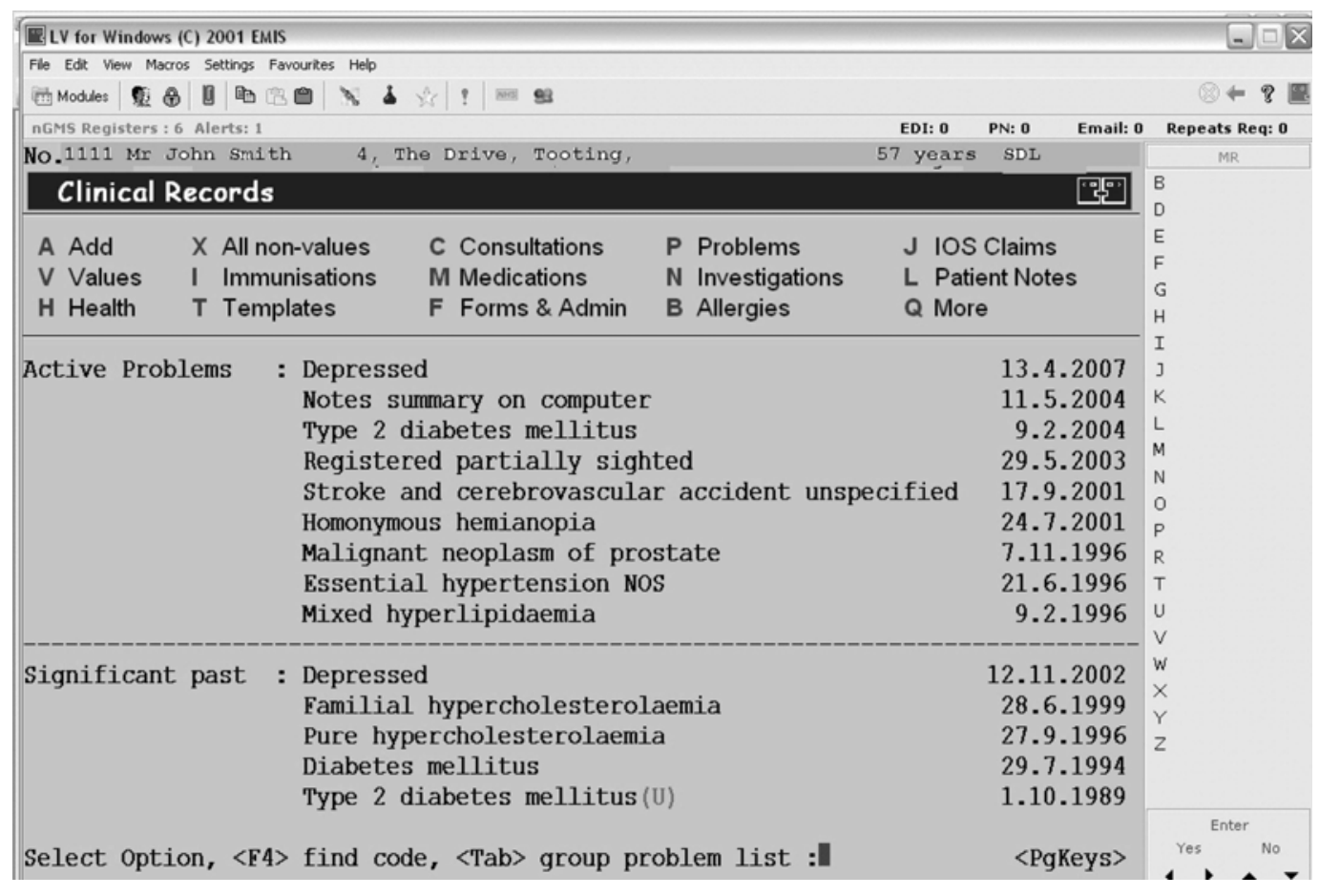

Figure 4. EMIS LV, the most used computer system in United Kingdom.

to sharing and integrating computerized records than technical constraints. The medical record remains largely a text file, with some images (mainly scanned letters) attached to it. Computer hardware is developing faster than the rate of growth of the primary care electronic record. Storage of our expanding records is less of a problem than in the early days, when coding systems were used for compactness and it would have been inconceivable to store images. Confidentiality and privacy are important practical and political issues. Currently, the NHS is hoping to run an "opt out" system where patients are automatically agreeing to participate in the NHS data-sharing arrangements, unless they say otherwise. There are also said to be "sealed envelopes" coming along into which sensitive health data can be placed which are not for sharing further. The goal is for key medical data to be available whenever they are needed within the NHS.

\section{ORGANIZATIONAL FACTORS}

Sufficient incentives and leadership have been in place at all levels of the NHS for primary care computerization to move forward. These incentives and leadership have been at the practice, locality, and national level.

\section{Practice/clinic incentives}

Practices and clinics have received government subsidies to computerize. The first wave of computerization occurred when "free computers for GPs" schemes were introduced in May 1987. It was hoped that secondary use of anonymized data would provide a sustainable business model, but this approach failed. Subsequently, part subsidy of computer purchase was provided to practices, with greater subsidies provided if practices took part in nationally promoted schemes. More recently, the NHS has taken over the upkeep and replacement of all the hardware within GP clinics. 


\section{Local health system}

Local health services have also encouraged adoption of national schemes, and many use anonymized practice data to assess health needs and information about the quality of care. Usually, local NHS managers are keen to promote participation in national schemes; a recent example would be the online outpatients booking scheme called "Choose and Book"-where practice computer systems were upgraded for participants. Localities also, with the permission of practices, extract anonymized data for clinical audit and to assess health needs, usually using a specially designed data extraction tool called Morbidity Information Query and Export Syntax (MIQUEST). In theory, MIQUEST allows the same data to be extracted from the different brands of GP computer system (NHS Connecting for Health). Most practitioners are very interested in how they are doing in comparison with their peer group and this becomes another incentive to record data reliably in the GP computer system; although inevitably, there may be some distortion of data recording when associated with quality payments (Teasdale et al., 2007).

\section{National organizational influences}

NHS level stimulus for the development of primary care IT has come from 2 directions: firstly, the promotion of explicit national standards for evidence-based practice and clinical governance; and secondly, from repeated rounds of national strategy, which have moved the NHS toward "enterprisewide" integration of IT systems. The National Service Frameworks and Cancer Plan, combined with the work of National Institute for Health and Clinical Excellence, have made standards explicit and when combined with a duty of clinical governance (to audit whether you are providing best practice) has led primary care clinicians to be willing to share de-identified clinical data. Simultaneous to this, ambitious plans have been put in place to integrate health service IT in England. This integration is far from perfect, but progress has been made in the large number of areas listed above. In Scotland and Wales, there has been less ambitious program for integration, but there are still IT strategies that support information sharing and data linkage.

\section{DISCUSSION}

The 4 elements within our model: clinician attitude; integration of IT into the clinical consultation; technological developments, and organizational factors have all been tilted toward the development of primary care IT.

There has been progressive evolution in the computerization of primary care in the United Kingdom. Primary care IT has evolved from small usually clinician-developed compact systems in individual practices, where data were just shared within that practice and which made some of its business processes more efficient. The next stage in development has been the incorporation of e-mail and Internet access via the NHS intranet (NHSnet); the more comprehensive recording and use of clinical data within the practice; linkage to pathology laboratories; and contributing anonymized data for secondary use.

We are now on the brink of the next hurdle in development, the possible integration of primary care IT into the wider NHS, resulting in data being shared at much greater distance. The distance across which data will be shared can be looked at in 3 dimensions: people, time, and place. With each of these dimensions, less will be known about the context within which it was recorded (de Lusignan \& Mimnagh, 2006). These data maybe analyzed by people with little understanding of the nature of medical practice in primary care (eg, how certain are we about the diagnosis of asthma?); there is a risk that knowledge not available at the time of recording is assumed at the time of analysis. Finally, data may be analyzed by someone looking at them, who is removed from the pressures of 10-minute consultations and unaware that the data entry form for diabetes care does code the result of a sensation test but does not use the diagnosis code for diabetic neuropathy.

While barely getting to grips with how to harness clinician-recorded primary care data, 
we also face the challenge of greater patient access to and ownership of data. We welcome people, having greater access to information about their healthcare and their medical records, but are also keen that we acknowledge that there is a dearth of experience of running open records like this other than "shared care" paper maternity records, which are the norm in the United Kingdom. It is also unclear at present whether the goal of integration with patient access will best be achieved through central contracts for specific services like "Health Space" or via the existing primary care vendor community.

Our top priority for further research is how to record sufficient context to avoid misinterpreting data recorded in primary care and then used elsewhere. Our recommendation as a stopgap is that teams analyzing data should

\section{REFERENCES}

Anderson, J., Aydin, C., \& Jay, S. (Eds.). (1994). Evaluating health care information systems: Methods and applications. London: Sage.

Ashworth, M., Jenkins, M., Burgess, K., Keynes, H., Wallace, M., Roberts, D., et al. (2005). Which general practices have higher list inflation? An exploratory study. Familiy Practice, 22(5), 529-531.

Bates, D. W. (2006). Invited commentary: The road to implementation of the electronic health record. Proceedings of the Baylor University Medical Center, 19(4), 311-2. Retrieved May 6, 2008, from http://www.

ncbi.nlm.nih.gov/pubmed/17106489?ordinalpos=1\& itool=EntrezSystem2.PEntrez.Pubmed Pubmed Results Panel.Pubmed RVDocSum

Benson, T. (2002a). Why general practitioners use computers and hospital doctors do not-Part 1: Incentives. BMJ, 325(7372), 1086-1089. Retrieved May 6, 2008, from http://www.pubmedcentral.

nih.gov/articlerender.fcgi?tool=pubmed\&pubmedid= 12424171

Benson, T. (2002b). Why general practitioners use computers and hospital doctors do not-Part 2: Scalability. BMJ, 325(7372), 1090-1093. Retrieved May 6, 2008, from

http://www.pubmedcentral.

nih.gov/articlerender.fcgi?tool=pubmed\&pubmedid= 12424172

Brennan, S. (2005). The NHS IT project: The biggest computer programme in the world... Ever! Oxford, England: Radcliffe.

de Lusignan, S. (2006). The optimum granularity for coding diagnostic data in primary care: Report of a work- always include an informatician who has a detailed understanding of the clinical context and systems in which the data under review were originally recorded. Much as most projects might insist on a statistician in the team.

\section{CONCLUSIONS}

A complex combination of increased willingness of individuals to use IT; the incorporation of IT into the clinical process: technological advances; and organizational change have all contributed to the development of UK Primary Care IT. Health services looking to implement IT in primary care could use this model to explore possible barriers to implementation. shop of the EFMI Primary Care Informatics Working Group at MIE 2005. Informatics in Primary Care, 14(2), 133137.

de Lusignan, S., Hague, N., van Vlymen, J., \& Kumarapeli, P. (2006). Routinely-collected general practice data are complex, but with systematic processing can be used for quality improvement and research. Informatics in Primary Care, 14(1), 59-66.

de Lusignan, S., \& Kati'c, M. (2007). UK and Croatia: Family practice, its medical records and computerisation in the context of an enlarged Europe. Informatics in Primary Care, 15(3), 169-173.

de Lusignan, S., \& Mimnagh, C. (2006). Breaking the first law of informatics: The Quality and Outcomes Framework (QOF) in the dock. Informatics in Primary Care, 14(3), 153-156.

de Lusignan, S., Sismanidis, C., Carey, I. M., DeWilde, S., Richards, N., \& Cook, D. G. (2005). Trends in the prevalence and management of diagnosed type 2 diabetes 1994-2001 in England and Wales. BMC Family Practice, 6(1), 13. Retrieved May 6, 2008, from http:// www.pubmedcentral.nih.gov/articlerender.fcgi?tool= pubmed\&pubmedid $=15784133$

de Lusignan, S., Teasdale, S., Little, D., Zapp, J., Zuckerman, A., Bates, D. W., et al. (2004). Comprehensive computerised primary care records are an essential component of any national health information strategy: Report from an international consensus conference. Informatics in Primary Care, 12(4), 255-

264. de Lusignan, S., \& Van Weel, C. (2006). The use of 
routinely collected computer data for research in primary care: Opportunities and challenges. Family Practice, 23(2), 253-263.

de Lusignan, S., Wells, S. E., Hague N. J., \& Thiru, K. (2003) Managers see the problems associated with coding clinical data as a technical issue whilst clinicians also see cultural barriers. Methods of Information in Medicine, 42(4), 416-422.

Department of Health. National Service Frameworks. Retrieved May 6, 2008, from http://www.dh.gov.uk/ en/Healthcare/NationalServiceFrameworks/index.htm Fitter, M., \& Cruickshank, P. (1983). The computer in the consulting room: A psychological framework. Behaviour and Information Technology, 1,81-

92.

Hannan, A., \& Webber, F. (2007). Towards a partnership of trust. Studies in Health Technology and Informatics, 127, 108-116.

Healthcare Commission. Homepage. Retrieved May 6, 2008, from www.healthcarecomission.org.uk Linder, J. A., Ma, J., Bates, D. W., Middleton, B., \& Stafford,

R. (2007). Electronic health record use and the quality of ambulatory care in the United States. Archives of Internal Medicine, 167(13), 1400-1405.

Mitchell, E., \& Sullivan, F. (2001). A descriptive feast but an evaluative famine: Systematic review of published articles on primary care computing during 1980-97. BMJ, 322(7281), 279-282.

NHS. National Institute for Health and Clinical Excel lence. Retrieved May 6, 2008, from http://www.nice. nhs.uk/

NHS Connecting for Health. MIQUEST. Retrieved May 6, 2008, from http://www.connectingforhealth.nhs.uk/ systemsandservices/data/miquest

Schade, C. P., Sullivan, F. M., de Lusignan, S., \& Madeley, J. (2006). e-Prescribing, efficiency, quality: Lessons from the computerization of UK family practice. Journal of the American Medical Informatics Association, 13(5), 470-475. Retrieved May 6, 2008, from http:// www.pubmedcentral.nih.gov $/$ picrender.fcgi?artid $=1561797 \&$ blobtype $=$ pdf

Taylor, H., \& Leitman, R. (2002). European physicians especially in Sweden, Netherlands and Denmark, Lead

U.S. in use of electronic medical records. Harris Interactive: Healthcare News. 2, 1-3. Retrieved May 6, 2008, from http://www.harrisinteractive.com/news/ newsletters/healthnews/HI HealthCareNews2002Vol2 Iss16.pdf

Teasdale, S., Bates, D., Kmetik, K., Suzewits, J., \& Brainbridge, M. (2007). Secondary uses of clinical data in primary care. Informatics in Primary Care, 15(3), 157-166.

Thiru, K., de Lusignan, S., \& Shaw, N. (2002). Paperless practice: A report from a research network. Informatics in Primary Care, 10(2), 89-94.

Van Der Lei, J. (1991). Use and abuse of computerstored medical records. Methods of Information in Medicine, 30, 79-80. 